\title{
High-capacity adsorbents from stainless steel slag for the control of dye pollutants in water
}

\author{
Lorenzo Plaza $^{1} \cdot$ Marta Castellote $^{1} \cdot$ Roman Nevshupa $^{1} \cdot$ Eva Jimenez-Relinque ${ }^{1}$
}

Received: 20 July 2020 / Accepted: 20 December 2020 / Published online: 2 January 2021

(C) The Author(s) 2021, corrected publication 2021

\begin{abstract}
Adsorbent materials for the control of dye pollutants in water were synthetized from stainless steel slag (SSS) using different acidbase treatments. Using $\mathrm{HCl}(\mathrm{SS}-\mathrm{Cl})$ and $\mathrm{HNO}_{3}\left(\mathrm{SS}_{-} \mathrm{NO}_{3}\right)$ produced high-capacity adsorbents, with BET areas of $232 \mathrm{~m}^{2} / \mathrm{g}$ and $110 \mathrm{~m}^{2} / \mathrm{g}$ respectively. Specifically, the SS-Cl had a structure of amorphous silica sponge. Treatment with $\mathrm{H}_{2} \mathrm{SO}_{4}\left(\mathrm{SS}_{-} \mathrm{SO}_{4}\right)$ did not enhance the adsorption capabilities with respect to the raw sample (SSS). Activated carbon (AC) was also tested as reference. The materials were characterized by X-ray diffraction (XRD), X-ray fluorescence (XRF), $\mathrm{N}_{2}$ adsorption-desorption isotherms, scanning electron microscopy (SEM), energy dispersive X-ray analysis (EDX) zeta potential, and infrared spectroscopy (FTIR). Batch adsorption experiments with methylene blue (MB) showed that the maximum sorption capacities were $9.35 \mathrm{mg} / \mathrm{g}$ and $8.97 \mathrm{mg} / \mathrm{g}$ for SS-Cl and SS-NO 3 at $240 \mathrm{~h}$, respectively. These values, even at slower rate, were close to the adsorption capacity of the AC $(9.72 \mathrm{mg} / \mathrm{g})$. This behavior has been attributed to the high porosity in the range of nanopores $(0.6-300 \mathrm{~nm})$ and the highsurface area for both samples. Preferential involvement of certain functional groups in the adsorption of dye ions on their surface indicative of chemisorption has been found. Although optimization, repeatability, and reproducibility of the process and environmental assessment have to be done before practical applications, these preliminary results indicate that application of these cost-effective adsorbents from raw SSS may be used in water pollution treatment and contribute to the sustainable development of the steel manufacturing industry.
\end{abstract}

Keywords Stainless steel slag $\cdot$ Adsorbent materials $\cdot$ BET surface area $\cdot$ Synthesis $\cdot$ Methylene blue $\cdot$ Water pollution control . Dye

\section{Introduction}

Steel manufacturing produces a significant amount of different slags (10-15\% by weight of the produced steel) (Proctor et al. 2000). It can be categorized as carbon steel slag and stainless steel slag (SSS) according to the type of steel, and as pretreatment slag, basic oxygen furnace slag (BOFS), electrical arc furnace slag (EAFS), ladle refining slag (LFS), and casting residue according to the steelmaking process

The original online version of this article was revised due to a retrospective Open Access order.

Responsible editor: Tito Roberto Cadaval Jr

Eva Jimenez-Relinque

eva.jimenez@csic.es

1 Spanish National Research Council, Eduardo Torroja Institute of Construction Science (IETcc-CSIC), C/ Serrano Galvache, 4, 28033 Madrid, Spain
(Manchisi et al. 2020; Yi et al. 2012). The steel slag mainly consists of $\mathrm{SiO}_{2}, \mathrm{CaO}, \mathrm{Fe}_{2} \mathrm{O}_{3}, \mathrm{FeO}, \mathrm{Al}_{2} \mathrm{O}_{3}, \mathrm{MgO}, \mathrm{MnO}$, and $\mathrm{P}_{2} \mathrm{O}_{5}$. The composition of steelmaking slags varies greatly from batch to batch, depending on the type of steel produced (e.g., carbon steel vs. stainless steels), the quality of starting raw materials and pretreatment process (Yi et al. 2012).

Based on steel production data of EU for the year 2018, around 16 million tons of steel slags are generated annually, $53 \%$ of which made up by BOFS, followed by EAFS (35\%) and LFS (12\%) (Euroslag 2018). For a long time, slags have been considered a problem, due to the high costs associated with their subsequent treatments, storage and disposal. However, the perception towards this waste is progressively changing and improving its reuse. Making reference again to EU data for the year 2018, $73 \%$ of these by-products are typically reused as artificial aggregates in road construction and cement production, but $13 \%$ are still landfilled, and $14 \%$ appear as internal storage (Euroslag 2018). To improve the current management practices for steel slags, recent studies 
have been focused on the development of recycling technologies, discovering the great potential of this type of waste as a precursor to synthesize products with high-added value. The valorization of such large amounts of steel slag are of great importance, both for the sustainability of the metallurgical industry and for the environment. One of the approaches to convert slag into a product with new potentialities is focused on exploring the effect of accelerated carbonation for storing point-source emissions of $\mathrm{CO}_{2}$ (Baciocchi et al. 2010; Bonenfant et al. 2008; Huijgen et al. 2005; Johnson 2000; Kodama et al. 2008; Lekakh et al. 2008; Santos et al. 2013). This conversion is accompanied by improving the mechanical properties, significant reduction in basicity, and stabilization of heavy metal leaching (Garcia-Blas et al. 2019; Johnson et al. 2003; Van Gerven et al. 2005). Black furnace slags (BFS) are used widely as supplementary materials in cements, having the cements type CEM V/B until a $49 \%$ of substitution of clinker by slags (Roy 1982), increasing in a big deal its durability (Castellote and Andrade 2006; Osborne 1999). However, the use of SSS has been constrained mainly due to the presence of heavy metals (Gomes and Pinto 2006), even though it can also be used as supplementary cementitious material (Shi 2004). The steel slag has been also used to remove metals (Repo et al. 2015; Zhou and Haynes 2011), phosphate, and dyes (Ahmed and Ahmaruzzaman 2016; Cheng et al. 2018; Xue et al. 2009) from contaminated water. However, the adsorption capacity of steel slag is relatively low mainly due to its low-specific surface area. Steel slag presents a mesoporous and mainly an amorphous structure with a typically low-specific surface area of less than $10 \mathrm{~m}^{2} / \mathrm{g}$ (Yi et al. 2012). This challenge notwithstanding, the efficacy of slagbased adsorbents can be significantly enhanced through purposeful activation to increase the specific surface area and density of adsorption sites on the surfaces of adsorbent particle. In addition, it is easy to separate from water due to its high density $\left(3.3-3.6 \mathrm{~g} / \mathrm{cm}^{3}\right)$. Different works are currently under way to find alternative conversion routes to develop sustainable slag-based materials for contaminated water treatment. Owing to $\mathrm{CaO}-\mathrm{SiO}_{2}-\mathrm{MgO}-\mathrm{Al}_{2} \mathrm{O}_{3}$ main system composition of steel slags, it can be used as a precursor for preparing a high-surface area calcium silicate hydrate, zeolite, or layered double hydroxide structures (Chiang et al. 2014; Kuwahara et al. 2009, 2010; Kuwahara et al. 2013). On this respect, activation routes based on the combination of acid-base treatments allow the adsorption capacities to be improved effectively. In Kuwahara et al. (2009), BFS is converted to a hydroxyapatite-zeolite compound using aqueous solutions of $\mathrm{H}_{3} \mathrm{PO}_{4}$ and $\mathrm{NaOH}$. In Kuwahara et al. (2010) and Kuwahara et al. (2013), a double-layered hydroxide based on $\mathrm{Ca}$ and zeolite structures through two-stage dissolution procedures of coprecipitation using aqueous solutions of $\mathrm{HCl}$ and $\mathrm{NaOH}$, respectively, was synthesized. In Chiang et al. (2014), a three-step process to transform BFS into two valuable products in parallel was developed: precipitated calcium carbonate and zeolite material. The materials synthesized in these works showed good adsorption properties allowing their use as adsorbents/solid ion exchangers for the treatment of wastewater and the elimination of dangerous substances in water such as heavy metal, dyes, arsenic, and phosphate ions. Furthermore, volatile organic compounds (VOCs) in the air are as adsorbents. Kuwahara et al. (2020) synthesized a mesoporous silica-calcium oxide compound from BFS by a hydrothermal dissolution process using formic acid as the solution. The synthesized composite material had a $\mathrm{CO}_{2}$ adsorption value of $18.8 \%$, and could be used for at least 10 cycles.

These precedents show that steel slags have great potential as a precursor to synthesize products with adsorbent characteristics. Efficient use of these low-cost sorbent materials can become an alternative technology for environmental remediation, and ultimately would lead to reduced waste generation. However, to maximize the chemical and economic potential of this type of waste, technologically viable conversion processes and implementable to the broadest range of slag type are needed. Most of the previous works were focused fundamentally on BFS-type slag residues without SSS ever being studied. The stainless steel market is witnessing a surge in demand, owing to the growth of end-user industries such as construction, automotive industry, and hygiene applications. Therefore, improving the utilization rate of stainless steel slag is an imperative way for the steel making industry to a sustainable development.

On the other hand, the use of dyes in many industries such as paint, textile, tannery, paper, leather, rubber, cosmetics, and plastics has resulted in the release of large amounts of colored toxic effluent and contaminated surface groundwater (Forgacs et al. 2004). About 10,000 types of commercial dyes are commonly used with around $7 \times 10^{5} \mathrm{t}$ of dyestuffs produced annually. Around $2 \%$ of them are released in effluents. The dyes significantly not only compromise the esthetic quality of water bodies but also may promote mutagenicity and carcinogenicity (Forgacs et al. 2004). Adsorption method has been widely accepted as one of the most effective dyes removal water treatment because it is rapid, effective, producing nontoxic by-product, and simple in operation design (Raval et al. 2016). Thus, the study and application of steel slag as lowcost adsorbent for the elimination of dye from contaminated wastewater is a very important issue that should be addressed.

In this work, the production and application of modified stainless steel slags (SSS) based adsorbents for the efficient removal of a cationic organic dye methylene blue (MB) from wastewater has been demonstrated. Three acid-base treatments were used to improve the adsorption property of ballmilled SSS for the first time. Physico-chemical characterizations were conducted to obtain the changes in properties of the steel slag before and after the modification. Comparative of 
reported main textural properties and adsorption capacities of the analyzed samples with the literature data of various modified slag materials and of a selected number of commercial adsorbents are also included.

\section{Experimental section}

\section{Acid-base treatments of raw stainless steel slag}

The SSS used in this study was provided by Acerinox Europa, S.A.U., Spain. Three acid-base treatments were explored using the following acids: $\mathrm{HCl}, \mathrm{HNO}_{3}$, and $\mathrm{H}_{2} \mathrm{SO}_{4}$ and the procedure shown in Fig. 1. The materials obtained were denoted according to the acid employed: SS-X, $\mathrm{X}=\mathrm{Cl}, \mathrm{NO}_{3}$, $\mathrm{SO}_{4}$. Before the treatments, the SSS was milled in a Micro Fine Mill Grinder at $5000 \mathrm{rpm}$ and sieved using a $120-\mu \mathrm{m}$ mesh. A weight of $5.0 \mathrm{~g}$ of the milled SSS was dissolved in $100 \mathrm{ml}$ of $3 \mathrm{M}$ acid solution. In order to avoid gelation, the solution was strongly stirred for $3 \mathrm{~h}$ at $50{ }^{\circ} \mathrm{C}$. After that, $4 \mathrm{M}$ $\mathrm{NaOH}$ aqueous solution was added dropwise until $\mathrm{pH}$ reached $12 \pm 0.1$. The volume was set to $200 \mathrm{ml}$ with water followed by stirring at $100{ }^{\circ} \mathrm{C}$ until dryness is reached after $18 \mathrm{~h}$. The

Fig. 1 Flow chart of acid-base treatments of the raw stainless steel slag (SSS) and image of the resulting treated slags. From left to right SS-Cl, $\mathrm{SS}_{-} \mathrm{NO}_{3}, \mathrm{SS}_{-} \mathrm{SO}_{4}$ formed solid was crushed, thoroughly rinsed with water, and dried in an oven at $100{ }^{\circ} \mathrm{C}$ overnight. The yield of the process was $5.4 \mathrm{~g}, 6.5 \mathrm{~g}$, and $8.2 \mathrm{~g}$ for SS-Cl, SS-NO ${ }_{3}$, and SS-SO respectively (Fig. 1).

\section{Characterization of the samples}

The X-ray diffraction patterns were obtained using a Bruker D8 Advance diffractometer with $\mathrm{CuK} \alpha$ radiation $(40 \mathrm{kV}$, $30 \mathrm{~mA}$ ). The elemental analysis of the samples were performed by X-ray fluorescence (XRF) using a X-ray Fluorescence Bruker S8 Tiger. The surface morphology and the composition analysis of samples were carried out by scanning electron microscope (SEM, JSM-6700F system) equipped with an energy dispersive X-ray fluorescence spectrometer (EDX), by which the optical analysis and elemental mapping were performed. A detailed analysis of the structure of the samples was performed by infrared spectroscopy.

Nitrogen adsorption-desorption isotherms were obtained using a conventional volumetric apparatus (ASAP2010) at $77 \mathrm{~K}$. The linear BET plots (SBET) were used to determine the equivalent surface area and the pore size distribution of samples was calculated by BJH method. Zeta potential

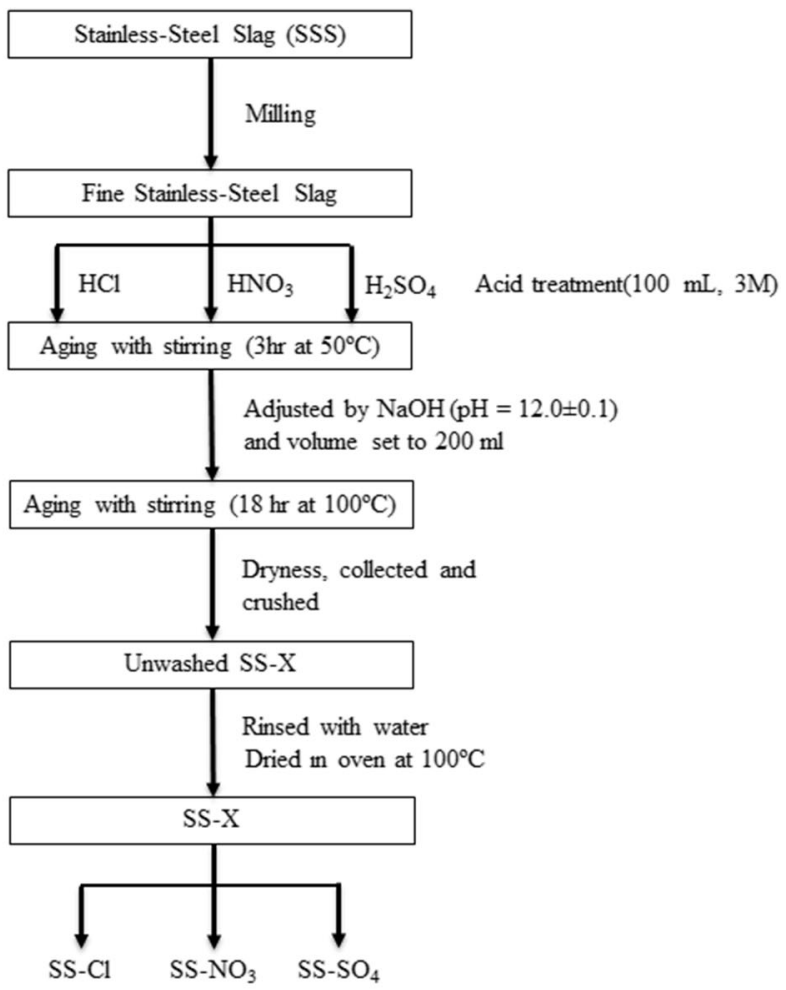

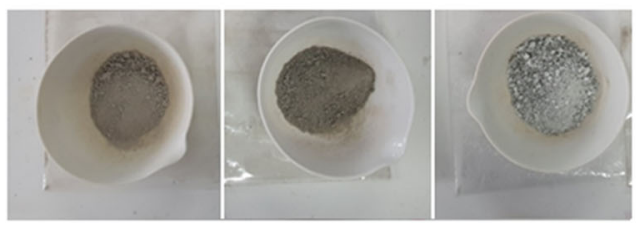


Fig. 2 XRD patterns of raw SSS and treated samples

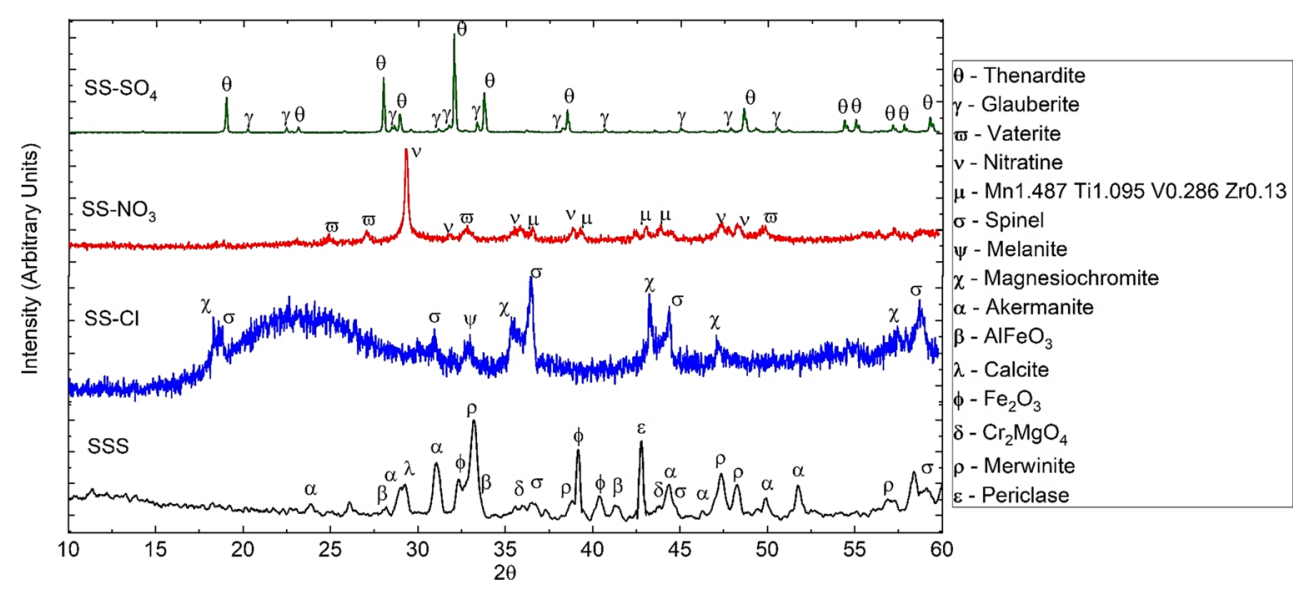

analysis was conducted on samples dispersed in deionized water $(10 \mathrm{mg} / 50 \mathrm{ml})$ using a Zetasizer (Zeta-meter 3.0+). Activated carbon (AC) was also tested to compare the results with a reference. AC sample was also milled in a Micro Fine Mill Grinder Culatti at $5000 \mathrm{rpm}$ and sieved using a $120-\mu \mathrm{m}$ mesh.

\section{Methylene blue adsorption tests}

Adsorption tests were performed using methylene blue (MB), which was chosen because of the neat charge at $\mathrm{pH}$ solution $(\mathrm{pH}=8.0)$, and benchmarked against untreated raw SSS and
AC. Prior to tests, all samples were preheated at $363 \mathrm{~K}$ to remove physisorbed $\mathrm{H}_{2} \mathrm{O}$.

In a first test, the adsorption performance was evaluated by mixing the solid sample $(30 \mathrm{mg})$ with $\mathrm{MB}$ solution $(10 \mathrm{ml}$, $30 \mathrm{ppm}$ ) in sealed glass vessels placed on a rotator for up to $240 \mathrm{~h}$ at $50 \mathrm{rpm}$. At predetermined time intervals, aliquots were taken and subsequently centrifuged to remove the solid sample. The decrease in absorbance of the supernatant solution was determined using Shimadzu UV-Vis spectroscopy. MB concentration was determined at $668 \mathrm{~nm}$ using a calibration line in the range $0-10 \mathrm{mg} / \mathrm{l}$. The adsorbance efficiency (\%) for MB was determined from the following formula:
Fig. 3 Elemental analysis composition of raw SSS and treated samples
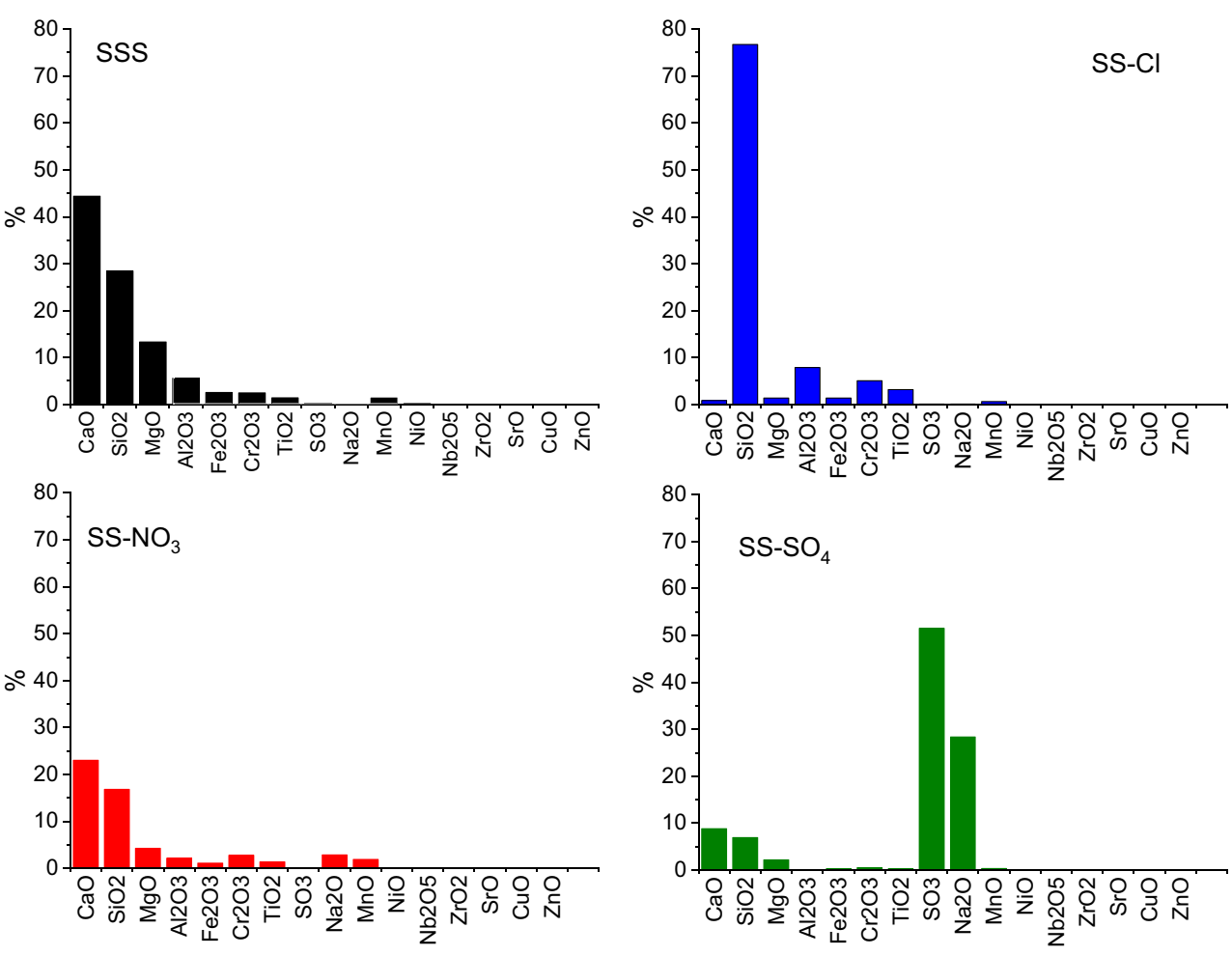


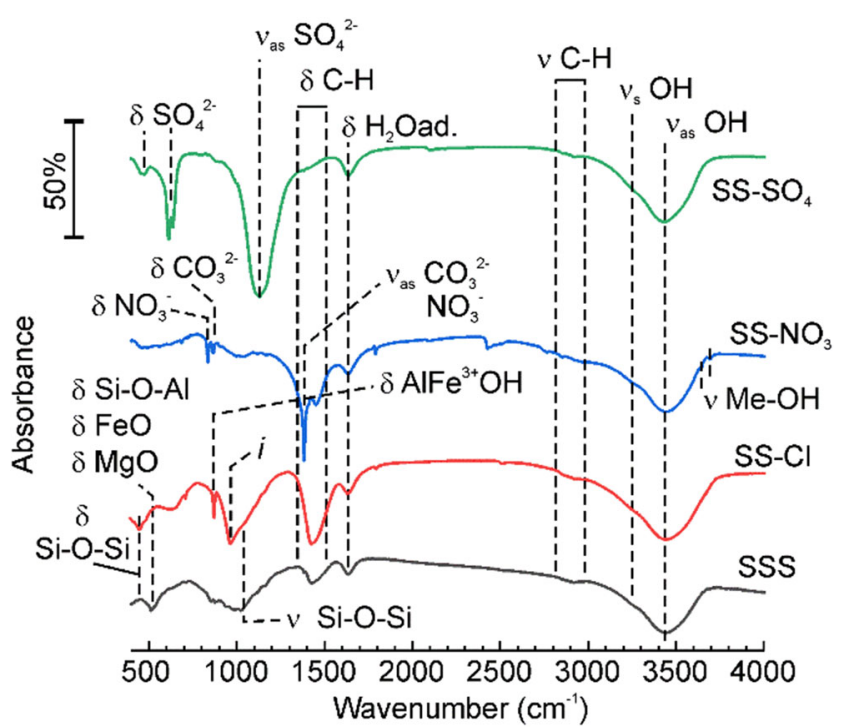

Fig. 4 FTIR spectra of the raw (SSS) and treated samples (SS-Cl, SS$\mathrm{NO}_{3}$, and $\mathrm{SS}_{-} \mathrm{SO}_{4}$ )

$(\%)=\frac{\left(C_{0}-C_{t}\right)}{C o} \times 100$

The amount of MB adsorbed, $q(\mathrm{mg} / \mathrm{g})$, was obtained as follows (Eq. 2):

$q=\frac{\left(C_{0}-C_{t}\right) \times V}{m}$ where $C_{0}$ and $C_{t}$ are the concentrations of $\mathrm{MB}(\mathrm{mg} / \mathrm{l})$ at times 0 and $t$ respectively, $V$ is the volume of the solution (1), and $m$ is the weight of the solid sample $(\mathrm{g})$.

In the second test, the samples $(50 \mathrm{mg})$ were saturated using a concentrated dissolution of the MB dye $(250 \mathrm{ml}$, $70 \mathrm{ppm}$ ) in sealed containers placed on a rotator for 2 weeks $(336 \mathrm{~h})$ at $50 \mathrm{rpm}$. After filtration and drying at $100{ }^{\circ} \mathrm{C}$ overnight, the solid samples were analyzed by FTIR (Thermo Scientific Nicolet 6700 Spectrometer) to identify the functional group that participate in the adsorption of dye ions on the surface.

\section{Results and discussion}

\section{Characterization}

Figure 2 shows the XRD patterns of the treated samples (SS$\mathrm{X}$ ), together with the raw SSS material. SSS exhibits diffraction peaks corresponding to mineral phases as akermanite $\left(\mathrm{Ca}_{2} \mathrm{Si}_{2} \mathrm{MgO}_{7}\right)$, merwinite $\left(\mathrm{Ca}_{3} \mathrm{Si}_{2} \mathrm{MgO}_{8}\right)$, calcite $\left(\mathrm{CaCO}_{3}\right)$, periclase $(\mathrm{MgO})$, and some metallic mixtures $\left(\mathrm{AlFeO}_{3}\right.$, $\mathrm{Fe}_{2} \mathrm{O}_{3}$, and $\mathrm{CrMgO}_{4}$ and $\mathrm{Mg}$-Al-Cr spinel structure). The diffraction patterns of the treated samples are quite different with respect to the SSS sample. The first observation is that there are less phases present in the treated samples. Some of the phases in SSS have disappeared, as a consequence of the strong acid treatments and some new phases are present. The
Fig. 5 SEM images at $\times 1000$ magnification of a SSS, $\mathbf{b}$ SS$\mathrm{NO}_{3}, \mathbf{c} \mathrm{SS}-\mathrm{Cl}$, and d SS-SO

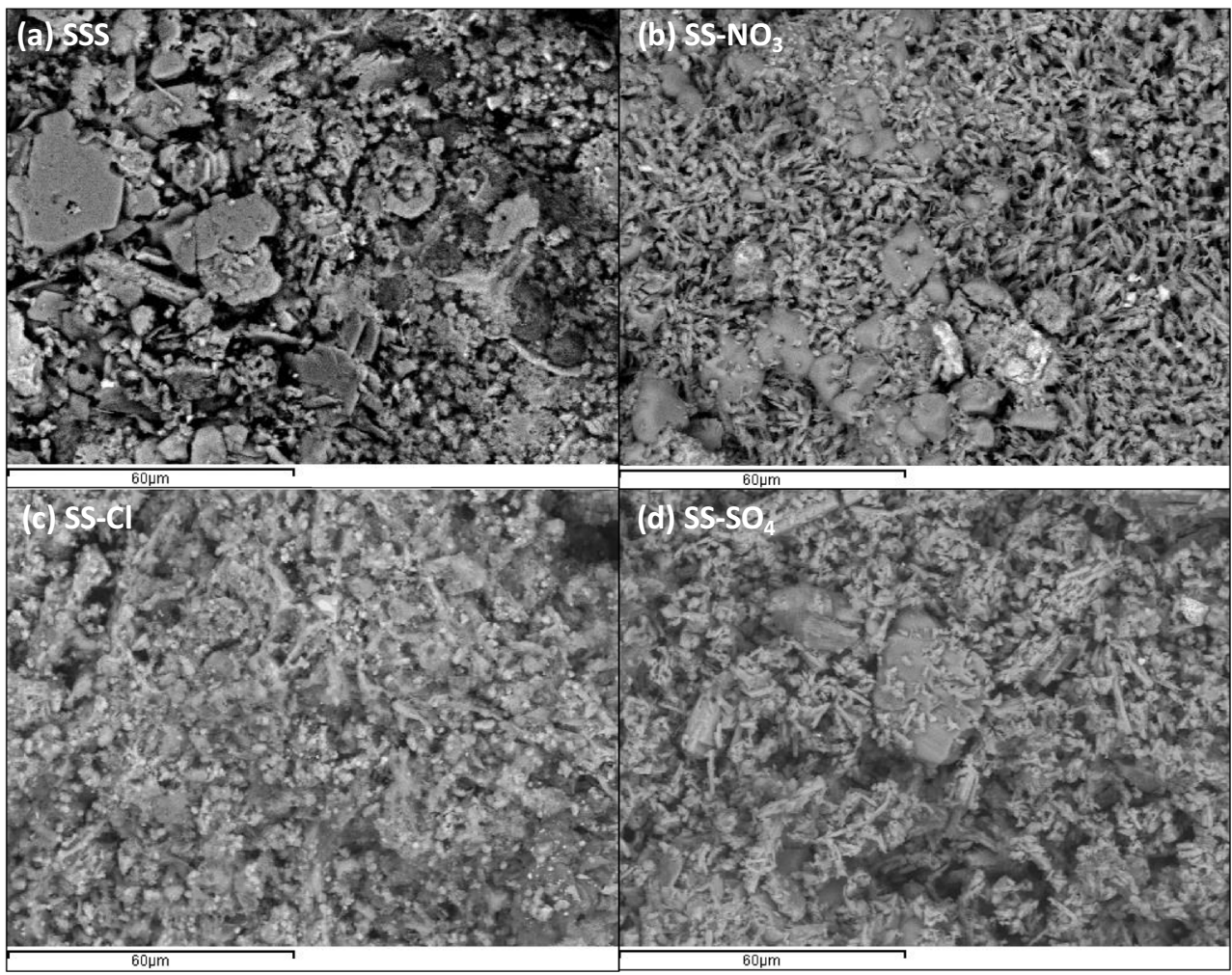


$\longrightarrow$ SSS $\multimap$ SS-Cl $\longrightarrow$ SS-NO ${ }_{3} \longrightarrow$ SS-SO $O_{4} \longrightarrow \mathrm{AC}$
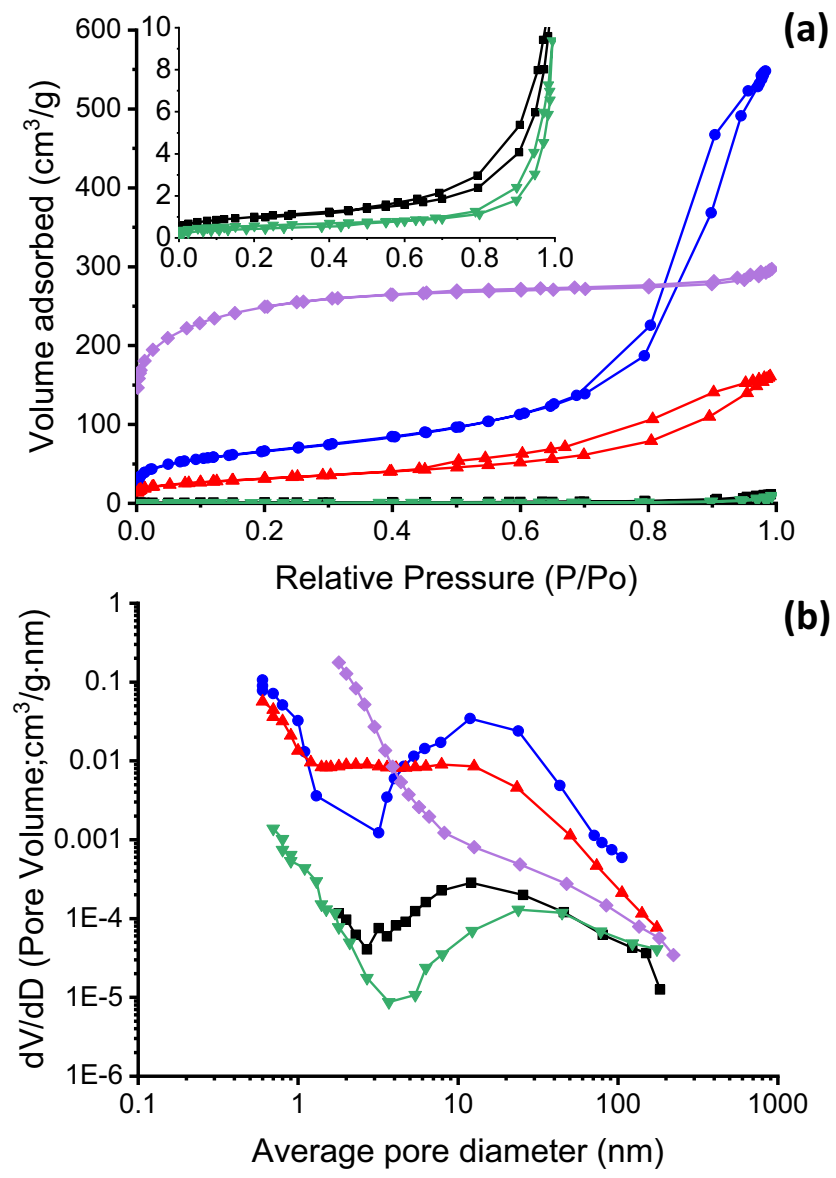

Fig. 6 a $\mathrm{N}_{2}$ adsorption-desorption isotherms and $\mathbf{b}$ differential pore size distribution in the range of nanopores

sample treated with $\mathrm{HCl}(\mathrm{SS}-\mathrm{Cl})$ presents high amorphous character with low-defined crystalline phases identified as magnesiochromite $\left(\mathrm{MgCr}_{2} \mathrm{O}_{4}\right)$, melanite $\left(\mathrm{Ca}_{3}\left(\mathrm{Fe}^{3+}\right)_{2}\left(\mathrm{SiO}_{4}\right)_{3}\right)$, and $\mathrm{Mg}-\mathrm{Al}-\mathrm{Fe}-\mathrm{Cr}$ cubic spinel structure. $\mathrm{SS}_{-} \mathrm{NO}_{3}$ and $\mathrm{SS}_{-} \mathrm{SO}_{4}$, did not exhibit amorphous structure, being the major crystalline phase identified in $\mathrm{SS}-\mathrm{NO}_{3}$, nitratine $\left(\mathrm{NaNO}_{3}\right)$, related with the interaction of the correspondent acid treatment and subsequent addition of $\mathrm{NaOH}$. Vaterite (polymorph of $\mathrm{CaCO}_{3}$ ) and a mixture structure of $\mathrm{Mn}-\mathrm{Ti}-\mathrm{V}-\mathrm{Zr}$ could be also observed. The $\mathrm{H}_{2} \mathrm{SO}_{4}$-treated samples $\left(\mathrm{SS}_{-} \mathrm{SO}_{4}\right)$ presented thenardite $\left(\mathrm{Na}_{2} \mathrm{SO}_{4}\right)$ and glauberite $\left(\mathrm{Na}_{2} \mathrm{Ca}\left(\mathrm{SO}_{4}\right)_{2}\right)$, which stemmed from the treatments.

The elemental composition of the treated samples (SS-X) and the raw SSS samples are shown in Fig. 3. The main components of SSS were $\mathrm{CaO}, \mathrm{SiO}_{2}, \mathrm{MgO}$, and $\mathrm{Al}_{2} \mathrm{O}_{3}$ and small amounts of transition metals such as $\mathrm{Fe}, \mathrm{Cr}$, Ti, and $\mathrm{Mn}$. The composition was in agreement with the XRD results. The SS$\mathrm{Cl}$ samples consisted mainly of $\mathrm{SiO}_{2}$ in amorphous form $(\sim$ $77 \%$ ). The fact that $\mathrm{Ca}$ vanished during the treatment was attributed to formation of soluble $\mathrm{CaCl}_{2}$, which was removed by washing. The subsequent addition of excess of $\mathrm{NaOH}$ may lead to precipitation of $\mathrm{Mg}$ - and Si-containing components, because of their insolubility in alkali solution (Kuwahara et al. 2009). The treatments with $\mathrm{HNO}_{3}\left(\mathrm{SS}-\mathrm{NO}_{3}\right)$ and $\mathrm{H}_{2} \mathrm{SO}_{4}\left(\mathrm{SS}_{-} \mathrm{SO}_{4}\right)$ caused decrease of both $\mathrm{CaO}$ and $\mathrm{SiO}_{2}$ and formation of other compounds, which did not leach during washing. We suppose that insoluble nitrates were formed during $\mathrm{HNO}_{3}$ treatments since nitrogen was not detected by XRF. In the $\mathrm{H}_{2} \mathrm{SO}_{4}$ treatment, $\mathrm{SO}_{3}$ and $\mathrm{Na}_{2} \mathrm{O}$ could be formed due to fixation of $\mathrm{Na}$ in the form of insoluble sulfates. This result is in good agreement with the above XRD identifications.

The FTIR results (Fig. 4) showed good correlation with the compositional analysis. The increase in Si concentration after $\mathrm{HCl}$ treatment corresponded to the increase of bands of deformation vibration of $\mathrm{Si}-\mathrm{O}-\mathrm{Si}$. Furthermore, the band at $512 \mathrm{~cm}^{-1}$, which was ascribed to vibrations of various metal-oxygen bonds such as $\mathrm{FeO}, \mathrm{MgO}$, and also Si-O-Al (Madejová et al. 2017), vanished after $\mathrm{HCl}$ treatment, but the band at $874 \mathrm{~cm}^{-1}$ appeared. The latter could be associated with $\mathrm{AlFe}^{3+} \mathrm{OH}$ (Madejová et al. 2017) and various $\mathrm{C}=\mathrm{C}$ and $\mathrm{C}=\mathrm{O}$ bonds (Socrates 1994). The wide band at $964 \mathrm{~cm}^{-1}$ can be due to superposition of various vibration bands of surface methyl groups, $\mathrm{C}-\mathrm{O}-\mathrm{C}$ and $\mathrm{C}=\mathrm{C}$. This is in line with the general increase of the bands corresponding to $\mathrm{sp}^{2}$ and $\mathrm{sp}^{3}$ hydrocarbons (Rusanov et al. 2015) on the SS-Cl. The $\mathrm{SS}_{-} \mathrm{NO}_{3}$ samples showed significant contribution from adsorbed $\mathrm{CO}_{2}$ and carbonate bands (Falk and Miller 1992; Kloprogge et al. 2002) that agrees observations of vaterite (calcium carbonate) in XRD spectrum of $\mathrm{SS}^{-N_{3}}$. The band of low intensity at $835 \mathrm{~cm}^{-1}$ could correspond to nitrates (Kloprogge et al. 2002). In the spectrum of the $\mathrm{SS}_{-} \mathrm{SO}_{4}$, the bands of sulfate were dominating (Das et al. 2014; Kloprogge et al. 2002; Pu et al. 2006; Wang et al. 2017), in agreement with the FRX data. In addition, all the spectra showed the bands of bonded $\mathrm{H}_{2} \mathrm{O}$ (Soria et al. 2007).

The SEM images of raw and treated samples at $\times 1000$ magnification are shown in Fig. 5 (a-d). All the samples had heterogeneous structure with large clusters and small detrital grains. For all treatments, the sample morphology significantly differed from the original SSS. Among the treated samples, SS-NO $\mathrm{N}_{3}$ and $\mathrm{SS}-\mathrm{SO}_{4}$, in agreement with the XRD, present nitrate and sulfate crystalline formations respectively distributed all around the samples with more opened macroporosity

Table $1 \mathrm{PH}$, conductivity and Z-potential of analyzed samples

\begin{tabular}{llll}
\hline Sample & $\mathrm{pH}$ & Conductivity $(\mu \mathrm{S} / \mathrm{cm})$ & $\zeta$-potential $(\mathrm{mV})$ \\
\hline $\mathrm{SSS}$ & 8.3 & 32.7 & -19.14 \\
$\mathrm{SS}-\mathrm{Cl}$ & 8.7 & 65.3 & -22.30 \\
$\mathrm{SS}^{-N_{3}}$ & 8.0 & 96.2 & -14.71 \\
$\mathrm{SS}_{3}$ & 7.3 & 360 & -35.15 \\
$\mathrm{AC}$ & 6.3 & 16.1 & -50.15 \\
\hline
\end{tabular}



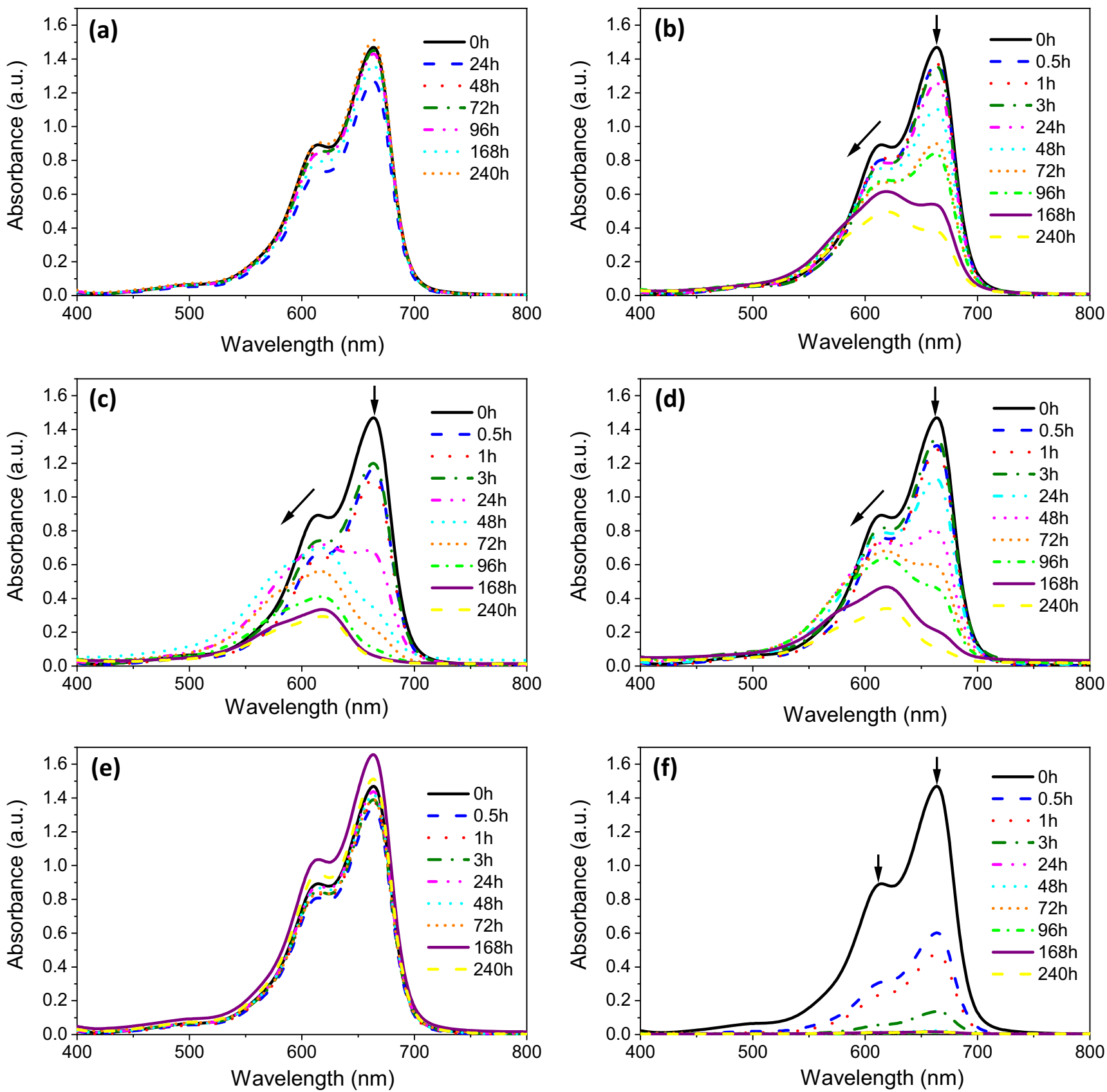

Fig. 7 Time evolution of absorption spectra of the MB solutions for a blank, b SSS, $\mathbf{c} \mathrm{SS}-\mathrm{Cl}, \mathbf{d} \mathrm{SS}_{-} \mathrm{NO}_{3}$, e SS-SO $\mathrm{S}_{4}$, and $\mathbf{f} \mathrm{AC}$

than in the case of SS-Cl, where the most amorphous character can be seen, exhibiting a more refined apparent porosity.

Figure 6a shows the $\mathrm{N}_{2}$ adsorption-desorption isotherm of all samples and the corresponding pore size distribution calculated according to Barrett-Joyner-Halenda (BJH) equation. The AC showed a reversible type I isotherm with steep uptake at very low $p / p_{0}$ due to narrow micropores and relatively small external surfaces (Thommes et al. 2015). The SSS and the SS$\mathrm{SO}_{4}$ exhibited the isotherms similar to type III with relatively weak adsorbent-adsorbate interactions. In turn, the isotherms for the $\mathrm{SS}_{-} \mathrm{NO}_{3}$ and $\mathrm{SS}-\mathrm{Cl}$ were type II, i.e., physisorption of gases on nonporous or macroporous adsorbents. All the treated samples showed a small hysteresis loop of type H3, which is characteristic for non-rigid aggregates of plate-like particles or for macropore network which is incompletely filled with pore condensate.

Figure $6 \mathrm{~b}$ gives the differential pore size distribution in the range of nanopores $(0.6-300 \mathrm{~nm})$. AC sample presents its maximum amount of pores at the lower size analyzed, showing a continuously diminishing trend as the pore diameter increases. SS-Cl, from its maximum at smaller sizes, diminishes to reach another maximum at around $10 \mathrm{~nm}$, being the sample with maximum porosity in this range. $\mathrm{SS}-\mathrm{NO}_{3}$ presents a stable amount of pores in the range $1-10 \mathrm{~nm}$, to 
$\rightarrow$ Blank $\multimap \mathrm{SSS} \longrightarrow \mathrm{SS}-\mathrm{Cl} \longrightarrow \mathrm{SS}-\mathrm{NO}_{3} \longrightarrow-\mathrm{SS}_{-} \mathrm{SO}_{4} \longrightarrow \mathrm{AC}$
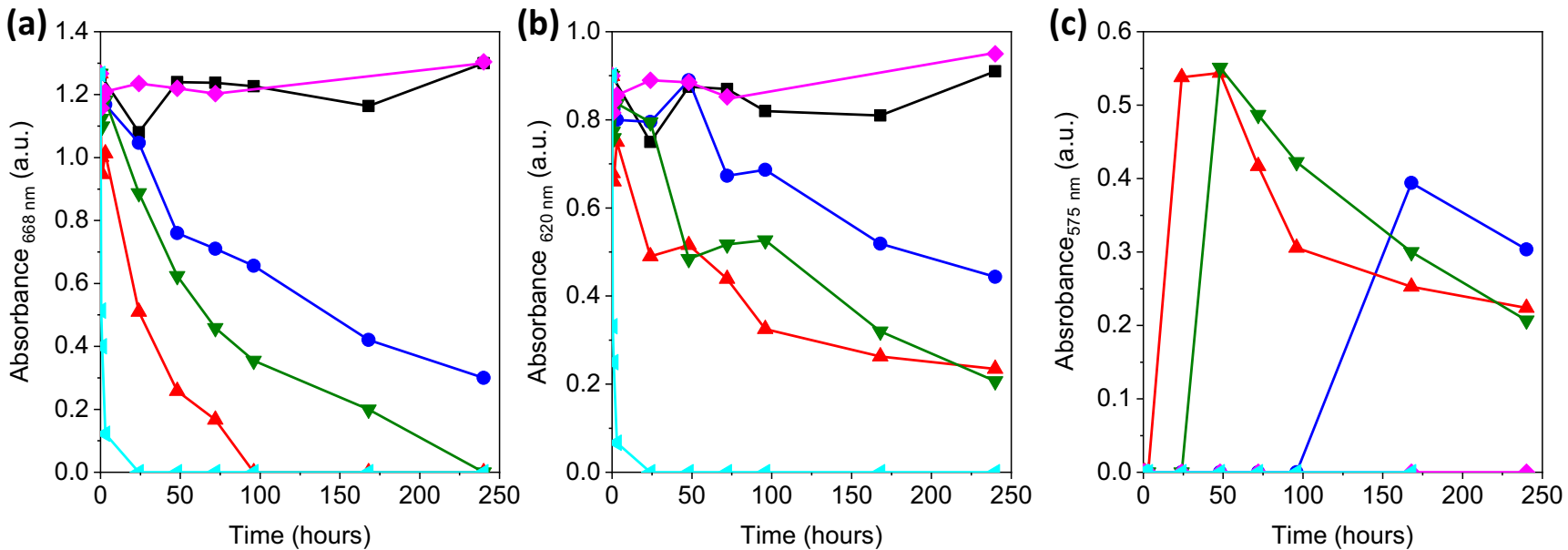

Fig. 8 Time profiles of absorbance of MB solution measured at $\mathbf{a}$ monomer, $\mathbf{b}$ dimer, and $\mathbf{c}$ trimer

diminish afterwards, having less amount of pores in this range with smaller mean diameter. SS and $\mathrm{SS}_{-} \mathrm{SO}_{4}$ have porosity an order of magnitude smaller than $\mathrm{SS}_{-} \mathrm{NO}_{3}$ porosity with higher mean pore diameter.

In agreement with the physisorption isotherms, the SSS and the $\mathrm{SS}_{-} \mathrm{SO}_{4}$ had lower BET area $\left(3.47 \mathrm{~m}^{2} / \mathrm{g}\right.$ and $1.97 \mathrm{~m}^{2} / \mathrm{g}$ respectively), and low porosity with large pore diameter. The average pore diameter decreased, while pore volume increased after $\mathrm{HCl}(\mathrm{SS}-\mathrm{Cl})$ and $\mathrm{HNO}_{3}\left(\mathrm{SS}_{-} \mathrm{NO}_{3}\right)$ treatments. The BET surface area of SS-Cl and SS- $-\mathrm{NO}_{3}$ are more than 67 and 32 times greater respectively than that of the unmodified SSS, which may imply a higher adsorption capacity. The reference activated carbon (AC) sample had the highest BET surface area $\left(813 \mathrm{~m}^{2} / \mathrm{g}\right)$, but the order of magnitude is the same that $\mathrm{SS}-\mathrm{Cl}$ and $\mathrm{SS}_{-} \mathrm{NO}_{3}$ as-prepared samples. According to these results, the treatment using $\mathrm{H}_{2} \mathrm{SO}_{4}$ yielded the worst results among all. Table 2 lists the values of the main textural properties of the tested samples.

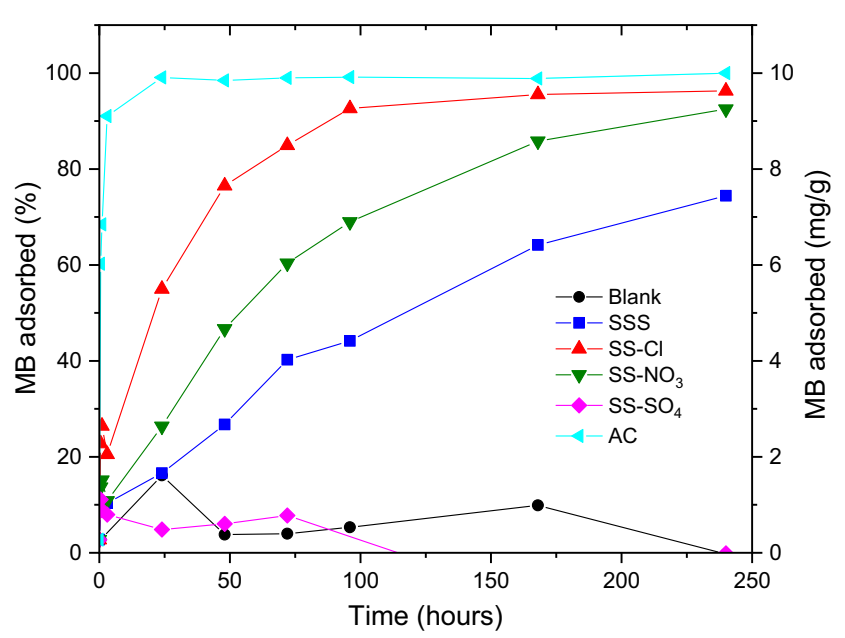

Fig. 9 Percentage and amount adsorbed of MB of all samples during the time of adsorption test
The $\mathrm{pH}$, conductivity, and Z-potential of the samples are given in Table 1. All treated samples maintained the basic character and negative surface charge as the SSS. The decreasing order of negative charge was the following $\mathrm{AC}>\mathrm{SS}$ $\mathrm{SO}_{4}>\mathrm{SS}-\mathrm{Cl}>\mathrm{SSS}>\mathrm{SS}-\mathrm{NO}_{3}$, whereas the conductivity increased as follows $\mathrm{AC}<\mathrm{SSS}<\mathrm{SS}-\mathrm{Cl}<\mathrm{SS}-\mathrm{NO}_{3}<<\mathrm{SS}_{-} \mathrm{SO}_{4}$. This ranking can be due to the existence of different amount of soluble components, mainly in $\mathrm{SS}_{-} \mathrm{NO}_{3}$ and $\mathrm{SS}_{-} \mathrm{SO}_{4}$, as previously identified by XRD.

\section{Adsorption tests}

The adsorption spectra of the MB solutions during the adsorption tests of the samples at different times are shown in Fig. 7 $(\mathrm{a}-\mathrm{f})$. At the beginning, the spectra showed two strong MB peaks with the maximum absorption at $\sim 668 \mathrm{~nm}$ and a small shoulder at $\sim 620 \mathrm{~nm}$ that was ascribed to the characteristic bands of MB monomers and dimers in solution, respectively (Yuan et al. 2019). In agreement with the low BET area, no $\mathrm{MB}$ adsorption happened on the $\mathrm{SS}_{-} \mathrm{SO}_{4}$, but the dye adsorbed on the AC quickly. For the SSS, SS-Cl, and $\mathrm{SS}_{-} \mathrm{NO}_{3}$, both monomer and dimer bands decreased during the test, while a broad band below $609 \mathrm{~nm}$ appeared. This band can be considered an indication of MB molecular aggregation on the samples surface, which can be assigned to the trimer structures (Horváth et al. 2014; Karaca et al. 2008; Yuan et al. 2019). To understand this behavior better, the adsorption spectra were fitted by the peaks corresponding to each MB form (monomer, dimer, and trimer) as shown in Fig. $8(\mathrm{a}-\mathrm{c})$. The absorbance at $620 \mathrm{~nm}$, corresponding to dimer structures, did not change or even increased at the beginning of the tests for SSS, $\mathrm{SS}-\mathrm{Cl}$, and $\mathrm{SS}_{-} \mathrm{NO}_{3}$. The trimer band at $575 \mathrm{~nm}$ reached maximum in the middle of the test for SS-Cl and $\mathrm{SS}_{-} \mathrm{NO}_{3}$ and in the second half of the test for SSS. These structures might result from the steric hindrance and a lower diffusion rate in 
Fig. 10 Relationship between BET Surface area and amount of MB adsorbed per gram of sample at $1 \mathrm{~h}$ of test

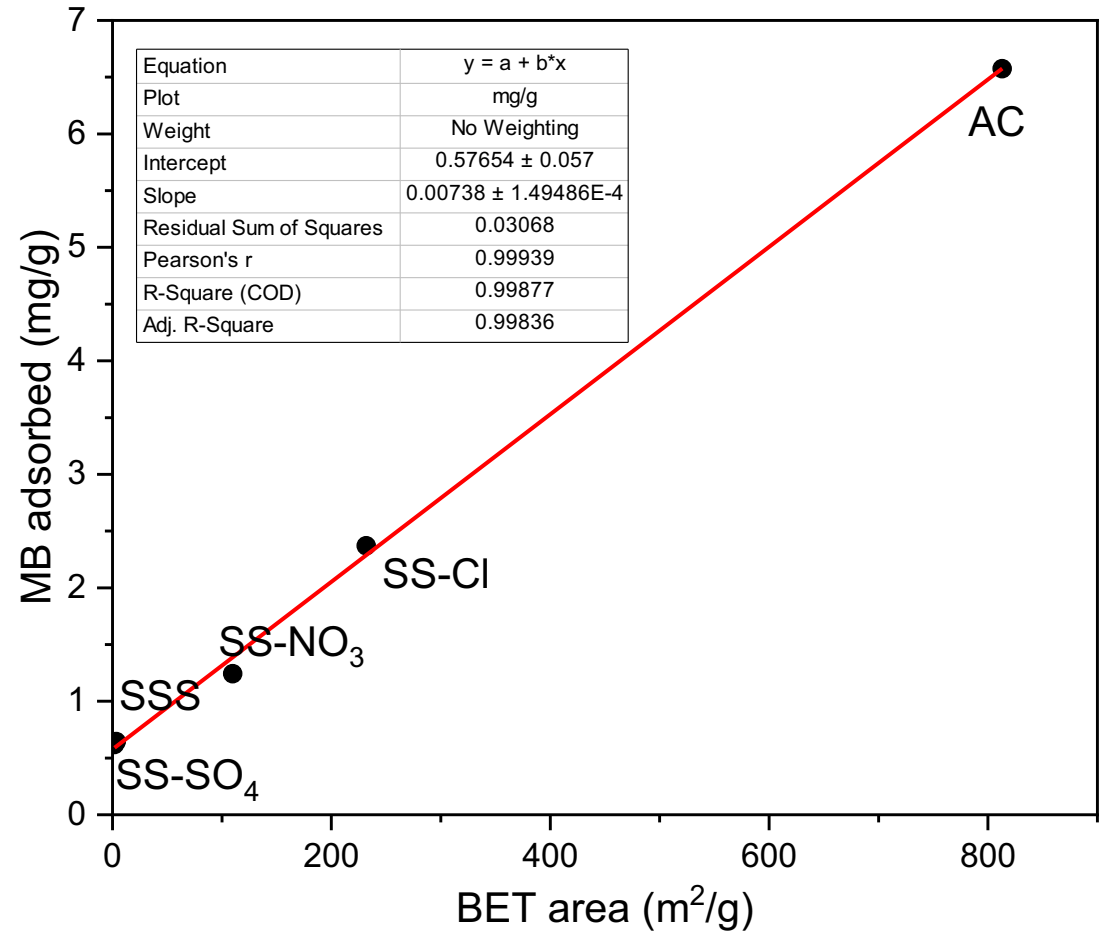

comparison with MB monomers. However, at longer adsorption duration, the agglomerate structures of MB may overcome diffusion resistance between the aqueous and solid phases.

The adsorption percentages and amount of MB adsorbed per gram of sample were calculated from the monomer band at $668 \mathrm{~nm}$ (Fig. 9). The adsorption of MB on AC completed during the first $24 \mathrm{~h}$ reaching the equilibrium at the maximum $9.72 \mathrm{mg} / \mathrm{g}$. This is due to the high negative surface charge, ordered microporous structure and large surface area. The SS$\mathrm{Cl}$ and $\mathrm{SS}-\mathrm{NO}_{3}$ also showed significate adsorption capability compared to the SSS. The enhanced adsorption capability of these samples is related to the improvement of BET area and pore volume parameters, thus providing more adsorption sites for $\mathrm{MB}$ removal. Although in the beginning the adsorption capacity was lower than for AC that could be related to the negative impact of the $\mathrm{MB}$ agglomerations at the surface, the SS-Cl and the $\mathrm{SS}_{-}-\mathrm{NO}_{3}$ reached $96 \%$ and $93 \%$, respectively (9.35 $\mathrm{mg} / \mathrm{g}$ and $8.97 \mathrm{mg} / \mathrm{g}$ respectively, in absolute value) after $240 \mathrm{~h}$. The maximum adsorption for SSS was $74 \%$ $(7.17 \mathrm{mg} / \mathrm{g})$. AC and SS-Cl reach the steady adsorption state during the test, which did not occur in the case of SSS and SS$\mathrm{NO}_{3}$. SS-SO $\mathrm{SO}_{4}$ did not presented significant adsorption of $\mathrm{MB}$, which was attributed to lower BET area than SSS. The good linear relationship between the adsorption capacity and BET surface area (Fig. 10) $\left(R^{2}=0.99\right)$ demonstrated that the amount of available surface sites is the critical parameter, which governs the adsorption capacity of the samples. The zeta potential should not have significant relevance concerning the adsorption capacity.
To provide further insight into MB adsorption on various samples FTIR analysis was carried out after dye adsorption on a second adsorption test (250 ml, 70 ppm, 336 h) (Fig. 11). The data are shown only for the samples, which had considerable adsorption capacity.

While for SSS, MB adsorption did not have any notable effect suggesting that the adsorption of dye molecules on SSS is through weak electrostatic interaction or van der Waals forces. Notwithstanding, MB adsorption on both SS-Cl and $\mathrm{SS}-\mathrm{NO}_{3}$ caused significant variation of the FTIR spectra and these variations were different between the samples. In the spectrum of the SS-Cl, the initial broad band of $\mathrm{CH}$ deformation vibration vanished and it was substituted by several weak and narrow bands identical to those of neat $\mathrm{MB}$, which were ascribed to $\mathrm{CH}$ and $\mathrm{C}=\mathrm{S}^{+}$(Ovchinnikov et al. 2016). However, the FTIR spectrum is not a superposition of the spectra of the substrate and neat MB since other MB bands were missing, while new bands appeared. The new wide and strong band centered at $1100 \mathrm{~cm}^{-1}$ could be due to the contributions of amine, $\mathrm{CO}$, and tertiary methyl or methyl-Al bonds (Socrates 1994). Similarly, the band at $800 \mathrm{~cm}^{-1}$ was ascribed to $\mathrm{Si}-\mathrm{C}$ and unsaturated esters including aromatic. These findings suggest that $\mathrm{MB}$ can adsorb on $\mathrm{SS}-\mathrm{Cl}$ via aromatic rings that does not affect vibration of $\mathrm{C}=\mathrm{S}$ bond. In case of $\mathrm{SS}-\mathrm{NO}_{3}$, no bands, which could be directly related to $\mathrm{MB}$, were found. The initial carbonate bands vanished, while a broad band of various $\mathrm{sp}^{2}$ and $\mathrm{sp}^{3}$ hydrocarbon bonds intensified. A narrow band at $875 \mathrm{~cm}^{-1}$ was ascribed to double bonds $\mathrm{C}=\mathrm{O}$ and $\mathrm{C}=\mathrm{C}$, while a wide band at $1024 \mathrm{~cm}^{-1}$ can be associated with C-O- and Si-O-stretching vibrations. Furthermore, both 


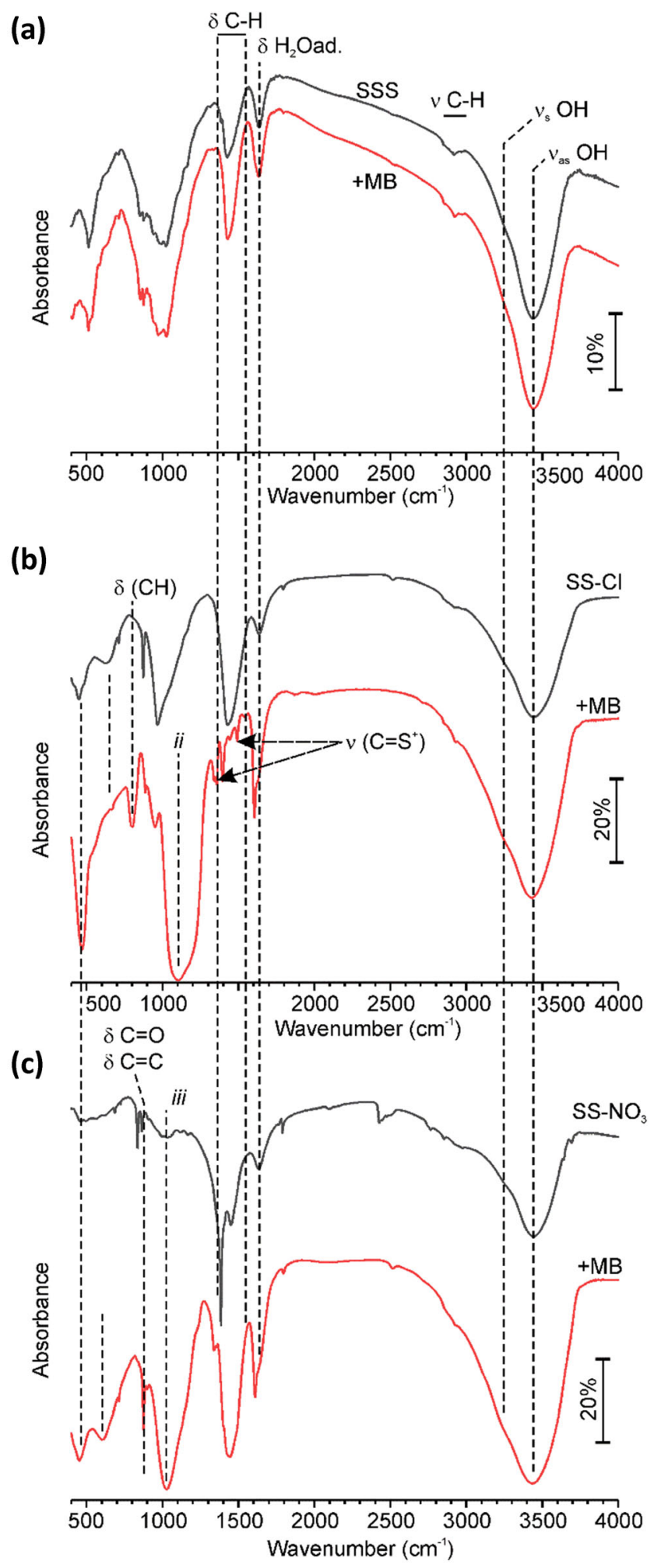

Fig. 11 FTIR spectra of various samples before and after MB adsorption: a SSS; b SS-Cl; c SS-NO

samples showed stronger $\mathrm{H}_{2} \mathrm{O}$ bands after $\mathrm{MB}$ adsorption. There is a remarkable change of the intensities of infrared bands with no change positions. These results indicated a preferential involvement of certain functional groups in the adsorption of dye ions on the surface of the treated samples.

The findings of BET surface area, pore volume, and average pore diameter from various studies of modified slag materials and a selected number of commercial adsorbents were also summarized in Table 2. Upon comparison with the literature of modified slag-based materials, it is revealed that the as-prepared material SS-Cl showed the highest surface area, outperforming other studies reported earlier, even many that also use the same reagents (dissolution and coprecipitation treatment: $\mathrm{HCl}-\mathrm{NaOH}$ ). Only, the study of Gao et al. (2017) and Kuwahara et al. (2010) reported similar or highest BET area results respectively. However, this enhanced result require a separation of the residual silica from BFS via a hydrothermal treatment and the use of additional reagent $\mathrm{NaAlO}_{2}$, resulting in production yield decreased and a cost increased. Besides this, it shows that the reported values of surface area on commercial adsorbents are in general larger that the reported values of modified slag-based materials, but the asprepared $\mathrm{SS}-\mathrm{Cl}$ and $\mathrm{SS}-\mathrm{NO}_{3}$ are in the same order. Furthermore, the synthetized samples show larger pore diameters than the reported values of commercial adsorbents. SS$\mathrm{Cl}$ and $\mathrm{SS}-\mathrm{NO}_{3}$ samples show values only comparable with the silica gel-large pore.

Table 3 summarizes the findings from various studies on the adsorption capacities of slag-based materials of various dyes in water. It should be noted that the most of the previous works using modified slag materials described in Table 2 were focused fundamentally on the removal in water of phosphate (Kuwahara et al. 2010; Kuwahara et al. 2013; Yu et al. 2015), metal ions (Kuwahara et al. 2013), and polycyclic aromatic hydrocarbons (Yang et al. 2018), or VOCs (Kuwahara et al. 2009), and $\mathrm{CO}_{2}$ capture in air (Kuwahara et al. 2020). Only Cheng et al. (2018), Gao et al. (2017), Xue et al. (2009) elucidated the efficacy of adsorption of dyes in water by slagbased materials. However, the adsorption data proposed by these authors and the data reported in this study vary greatly, possibly compounded by the heterogeneous nature of the slags, and the different dyes and experimental conditions used (see Table 3). Thus, the interpretation and comparison of adsorption capacities between the studies are complicated.

In spite of these comparative difficulties, the maximum absorption capability of this study, that corresponding with $\mathrm{SS}-\mathrm{Cl}(9.35 \mathrm{mg} / \mathrm{g})$ is lower than the data reported by Cheng et al. (2018), and it requires more time to achieve the equilibrium. Despite both studies using similar experimental conditions and the same dye, the efficiency of our modified slag material, whose BET surface area is more than three time greater, and seems that can be limited by the MB amount used in the experiments (almost the entire dye solution was adsorbed, 96\%). The adsorption efficiency is to be highly dependent on the initial dye concentration. The percentage adsorption decrease with increase in initial dye concentration 


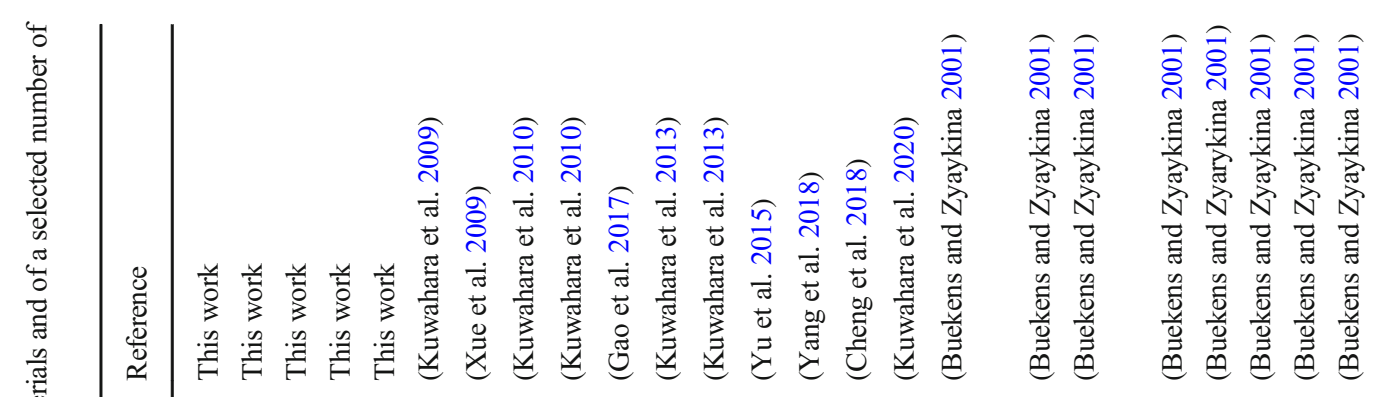$$
\text { 政 }
$$$$
\text { . }
$$

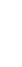

$$
\text { . }
$$

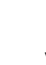




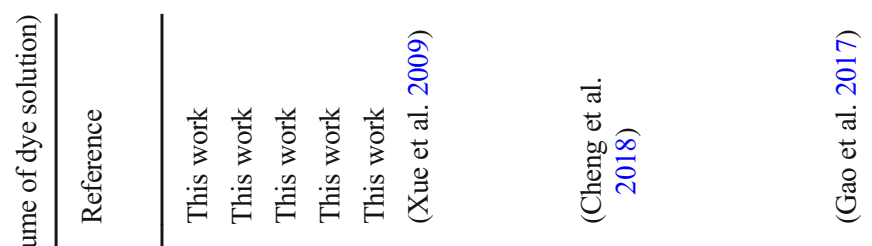

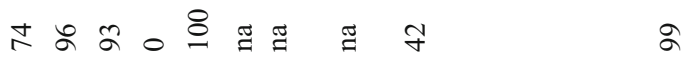

हो

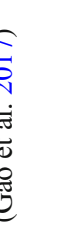

का

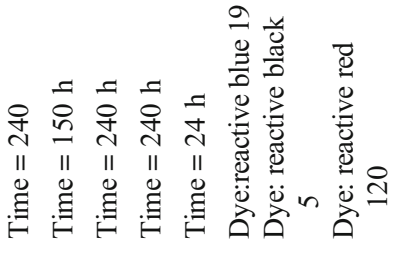
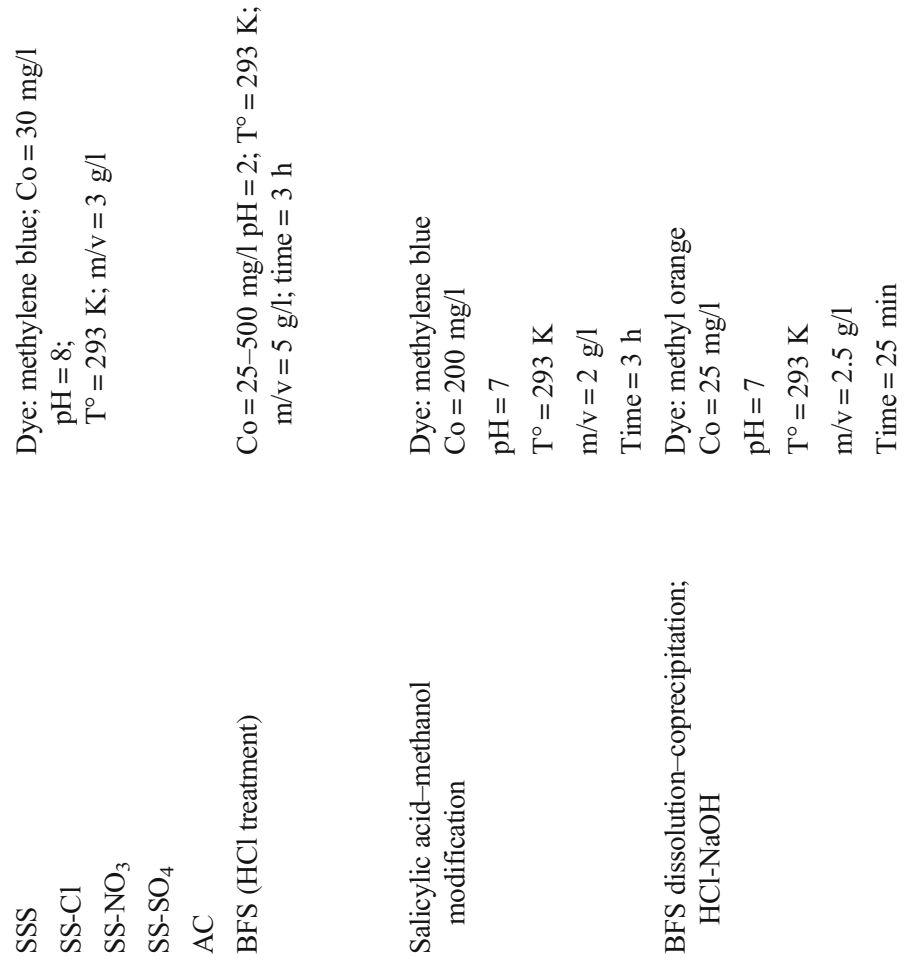

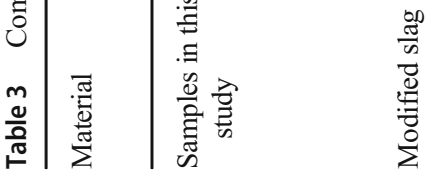


but the actual amount of dye adsorbed per unit mass of adsorbent increased with increase in dye concentration in the test solution.

Nevertheless, the various studies highlighted so far, and the present study using stainless steel slags for the first time, have converged on the technical merit of slags can be used as adsorbents for remediating industrial effluents and wastewaters. Besides this, the obtained results remark that the studied conversion processes may enable the fabrication of potential adsorbents through low complex chemical components, at low cost and abundant supply, which would meet the requirement for mass production. The USGS-MRP (United States Geological Survey-Mineral Resources Program) stablished that the selling prices in 2015 of steel slag ranged from $\$ 1.65$ to $\$ 36.93$ per metric ton, with an average of $\$ 5.49$ per metric ton. The market for slag is likely to fluctuate, but the government and industry efforts to promote "sustainable" materials and practices and recycling in general likely will favor the increased use of slags and it cost lowering. Furthermore, the chemicals used in this study for the transformation to adsorbent can be cheaply provided by the industrial supplies, without the use of costly calcium- or silicon-containing chemical or multiple pure metal-containing chemical sources. Comparison with the other adsorbents such as activated alumina (US\$ $0.60-1.19 \times 10^{3} \mathrm{t}^{-1}$ ) (Liu et al. 2010), carbon nanotubes (US\$ $441.85 \times 10^{6} \mathrm{t}^{-1}$ ), modified graphene oxide (about US\$ $60 \times 10^{4} \mathrm{t}^{-1}$ ), zeolite (US\$ 30-120 $\times 10^{3} \mathrm{t}^{-1}$ ) (Rafatullah et al. 2010), and coconut shell-based activated carbon (US\$ $0.88-1.32 \times 10^{3} \mathrm{t}^{-1}$ ) (Liu et al. 2010), the cost of modified SSS ( $\mathrm{SS}-\mathrm{Cl}$ and $\mathrm{SS}-\mathrm{NO}_{3}$ ) will surely be much lower. The versatility the described synthetic methods is also enhanced by the fact that a settling process can easily separate the adsorbent and the liquid after the treatment, which enables the reuse of the adsorbent due to its high density.

\section{Conclusions}

A three acid-base conversion process on raw stainless steel slags (SSS) to obtain low-cost adsorbents was proven using $\mathrm{HCl}$, $\mathrm{HNO}_{3}$, and $\mathrm{H}_{2} \mathrm{SO}_{4}$ and subsequently $\mathrm{NaOH}$ reported earlier. A porous silica matrix with a mean pore diameter of $14.61 \mathrm{~nm}$ (in the range $0.6-300 \mathrm{~nm}$ ) and a large surface area BET of $232.11 \mathrm{~m}^{2} / \mathrm{g}$ was successfully synthesized using $\mathrm{HCl}$ (SS-Cl) as a dissolving agent, while the use of $\mathrm{HNO}_{3}\left(\mathrm{SS}_{\mathrm{NO}}\right)$ resulted in the formation of calcium silicate materials with a pore diameter of $9.04 \mathrm{~mm}$ and $110.07 \mathrm{~m}^{2} / \mathrm{g}$. In contrast, the treatment with $\mathrm{H}_{2} \mathrm{SO}_{4}$ generated a low-surface area material $\left(1.97 \mathrm{~m}^{2 /} \mathrm{g}\right)$, even lower than the raw SSS $\left(3.47 \mathrm{~m}^{2} / \mathrm{g}\right)$. SS-Cl and SS-NO $\mathrm{NO}_{3}$ samples exhibited good adsorption performance $(9.35 \mathrm{mg}$ and $8.97 \mathrm{mg} / \mathrm{g}$ respectively) for removing methylene blue (MB) from water. Even though the time required for adsorption was much longer, both samples exhibited adsorption capabilities comparable to the activated carbon used as a reference $(9.72 \mathrm{mg} / \mathrm{g})$. The enhanced adsorption capability of these samples is related to the improvement of BET. The obtained results demonstrated that SSS waste material can be valorized by conversion into a low-cost adsorbent. Although more detailed studies on process optimization, repeatability, and reproducibility of the process and environmental assessment need to be done before practical applications, the conversion processes could be considered to be beneficial from the viewpoint of realizing an effective use of SSS, and will offer novel solutions not only to waste management problems but to environmental problems, since the synthesized product can be used as a versatile adsorbent.

Authors' contributions Lorenzo Plaza: writing — original draft, investigation; Marta castellote: conceptualization, writing - review and editing; Roman Nevshupa: writing - review and editing, Eva Jimenez-Relinque: conceptualization, methodology, writing - review and editing, project administration.

Funding information This study is financially supported by the Fundación General del CSIC (Programa ComFuturo) for the research contract of Eva Jimenez-Relinque and that of the Community of Madrid through the program "Garantía Juvenil" for the pre-doctoral contract of Lorenzo Plaza (PEJD-2018-PRE/AMB-9387).

\section{Compliance with ethical standards}

Competing interests The authors declare that the research was conducted in the absence of any commercial or financial relationships that could be construed as a potential conflict of interest.

Open Access This article is licensed under a Creative Commons Attribution 4.0 International License, which permits use, sharing, adaptation, distribution and reproduction in any medium or format, as long as you give appropriate credit to the original author(s) and the source, provide a link to the Creative Commons licence, and indicate if changes were made. The images or other third party material in this article are included in the article's Creative Commons licence, unless indicated otherwise in a credit line to the material. If material is not included in the article's Creative Commons licence and your intended use is not permitted by statutory regulation or exceeds the permitted use, you will need to obtain permission directly from the copyright holder. To view a copy of this licence, visit http://creativecommons.org/licenses/by/4.0/.

\section{References}

Ahmed MJK, Ahmaruzzaman M (2016) A review on potential usage of industrial waste materials for binding heavy metal ions from aqueous solutions. J Water Process Eng 10:39-47

Baciocchi R, Costa G, Di Bartolomeo E, Polettini A, Pomi R (2010) Carbonation of stainless steel slag as a process for $\mathrm{CO}_{2}$ storage and slag valorization. Waste Biomass Valorization 1:467-477

Bonenfant D, Kharoune L, Sauve S, Hausler R, Niquette P, Mimeault M, Kharoune $\mathrm{M}$ (2008) $\mathrm{CO}_{2}$ sequestration potential of steel slags at ambient pressure and temperature. Ind Eng Chem Res 47:7610 7616

Buekens A, Zyaykina N (2001): Adsorbents and adsorption processes for pollution control. Pollut Control Technol 2 
Castellote M, Andrade C (2006) Round-Robin test on methods for determining chloride transport parameters in concrete. Mater Struct 39: 955

Cheng M, Zeng G, Huang D, Lai C, Liu Y, Zhang C, Wang R, Qin L, Xue W, Song B (2018) High adsorption of methylene blue by salicylic acid-methanol modified steel converter slag and evaluation of its mechanism. J Colloid Interface Sci 515:232-239

Chiang YW, Santos RM, Elsen J, Meesschaert B, Martens JA, Van Gerven T (2014) Towards zero-waste mineral carbon sequestration via two-way valorization of ironmaking slag. Chem Eng J 249:260 269

Das G, Kakati N, Lee SH, Karak N, Yoon YS (2014) Water soluble sodium sulfate nanorods as a versatile template for the designing of copper sulfide nanotubes. J Nanosci Nanotechnol 14:4455-4461

Euroslag (2018) https://www.euroslag.com/products/statistics/statistics-2018

Falk M, Miller AG (1992) Infrared spectrum of carbon dioxide in aqueous solution. Vib Spectrose 4:105-108

Forgacs E, Cserhati T, Oros G (2004) Removal of synthetic dyes from wastewaters: a review. Environ Int 30:953-971

Gao H, Song Z, Zhang W, Yang X, Wang X, Wang D (2017) Synthesis of highly effective absorbents with waste quenching blast furnace slag to remove Methyl Orange from aqueous solution. J Environ Sci 53:68-77

Garcia-Blas N, Jimenez-Relinque E, Nevshupa R, Castellote M (2019) Interaction dynamics between a contaminated dredged sediment and extracting solutions of different nature. J Soils Sediments 20:2664-2671

Gomes J, Pinto C (2006) Leaching of heavy metals from steelmaking slags. Rev Metal 42:409-416

Horváth E, Szilágyi I, Forró L, Magrez A (2014) Probing titanate nanowire surface acidity through methylene blue adsorption in colloidal suspension and on thin films. J Colloid Interface Sci 416:190-197

Huijgen WJ, Witkamp G-J, Comans RN (2005) Mineral $\mathrm{CO}_{2}$ sequestration by steel slag carbonation. Environ Sci Technol 39:9676-9682

Johnson D (2000): Accelerated carbonation of waste calcium silicate materials. Soc Chem Indu Sci Lect Series

Johnson D, MacLeod C, Carey P, Hills C (2003) Solidification of stainless steel slag by accelerated carbonation. Environ Technol 24:671-678

Karaca S, Gürses A, Açıkyıldız M, Ejder M (2008) Adsorption of cationic dye from aqueous solutions by activated carbon. Microporous Mesoporous Mater 115:376-382

Kloprogge JT, Wharton D, Hickey L, Frost RL (2002) Infrared and Raman study of interlayer anions $\mathrm{CO}_{3}{ }^{2-}, \mathrm{NO}_{3}{ }^{-}, \mathrm{SO}_{4}{ }^{2-}$ and $\mathrm{ClO}_{4}{ }^{-}$ in Mg/Al-hydrotalcite. Am Mineral 87:623-629

Kodama S, Nishimoto T, Yamamoto N, Yogo K, Yamada K (2008) Development of a new $\mathrm{pH}$-swing $\mathrm{CO} 2$ mineralization process with a recyclable reaction solution. Energy 33:776-784

Kuwahara Y, Ohmichi T, Kamegawa T, Mori K, Yamashita H (2009) Synthesis of hydroxyapatite-zeolite composite material from disposed steel slag and investigation of its structural and physicochemical characteristics. Chem Lett 38:626-627

Kuwahara Y, Ohmichi T, Kamegawa T, Mori K, Yamashita H (2010) A novel conversion process for waste slag: synthesis of a hydrotalcitelike compound and zeolite from blast furnace slag and evaluation of adsorption capacities. J Mater Chem 20:5052-5062

Kuwahara Y, Tamagawa S, Fujitani T, Yamashita H (2013) A novel conversion process for waste slag: synthesis of calcium silicate hydrate from blast furnace slag and its application as a versatile adsorbent for water purification. J Mater Chem A 1:7199-7210

Kuwahara Y, Hanaki A, Yamashita H (2020): A direct conversion of blast furnace slag to a mesoporous silica-calcium oxide composite and its application in $\mathrm{CO}_{2}$ captures. Green Chem

Lekakh SN, Rawlins CH, Robertson DG, Richards V, Peaslee KD (2008) Kinetics of aqueous leaching and carbonization of steelmaking slag. Metall Mater Trans B Process Metall Mater Process Sci 39:125-134
Liu W, Zhang J, Zhang C, Wang Y, Li Y (2010) Adsorptive removal of $\mathrm{Cr}$ (VI) by Fe-modified activated carbon prepared from Trapa natans husk. Chem Eng J 162:677-684

Madejová J, Gates WP, Petit S (2017) Chapter 5 - IR spectra of clay minerals. In: Gates WP, Kloprogge JT, Madejová J, Bergaya F (eds) Developments in Clay Science. Elsevier, Amsterdam, pp 107-149

Manchisi J, Matinde E, Rowson NA, Simmons MJ, Simate GS, Ndlovu S, Mwewa B (2020) Ironmaking and steelmaking slags as sustainable adsorbents for industrial effluents and wastewater treatment: a critical review of properties, performance, challenges and opportunities. Sustainability 12:2118

Osborne G (1999) Durability of Portland blast-furnace slag cement concrete. Cem Concr Compos 21:11-21

Ovchinnikov OV, Evtukhova AV, Kondratenko TS, Smirnov MS, Khokhlov VY, Erina OV (2016) Manifestation of intermolecular interactions in FTIR spectra of methylene blue molecules. Vib Spectrosc 86:181-189

Proctor D, Fehling K, Shay E, Wittenborn J, Green J, Avent C, Bigham R, Connolly M, Lee B, Shepker T (2000) Physical and chemical characteristics of blast furnace, basic oxygen furnace, and electric arc furnace steel industry slags. Environ Sci Technol 34:1576-1582

Pu Y-C, Hwu JR, Su W-C, Shieh D-B, Tzeng Y, Yeh C-S (2006) Waterdissolvable sodium sulfate nanowires as a versatile template for the fabrication of polyelectrolyte- and metal-based nanotubes. J Am Chem Soc 128:11606-11611

Rafatullah M, Sulaiman O, Hashim R, Ahmad A (2010) Adsorption of methylene blue on low-cost adsorbents: a review. J Hazard Mater 177:70-80

Raval NP, Shah PU, Shah NK (2016) Adsorptive amputation of hazardous azo dye Congo red from wastewater: a critical review. Environ Sci Pollut Res 23:14810-14853

Repo E, Warchoł JK, Westholm LJ, Sillanpää M (2015) Steel slag as a low-cost sorbent for metal removal in the presence of chelating agents. J Ind Eng Chem 27:115-125

Roy D (1982): Hydration, structure, and properties of blast furnace slag cements, mortars, and concrete, J Proc, pp. 444-457

Rusanov A, Nevshupa R, Martin J-M, Garrido MÁ, Roman E (2015) Tribochemistry of hydrogenated amorphous carbon through analysis of Mechanically Stimulated Gas Emission. Diam Relat Mater 55:32-40

Santos RM, Van Bouwel J, Vandevelde E, Mertens G, Elsen J, Van Gerven T (2013) Accelerated mineral carbonation of stainless steel slags for $\mathrm{CO}_{2}$ storage and waste valorization: effect of process parameters on geochemical properties. Int J Greenhouse Gas Control 17:32-45

Shi C (2004) Steel slag - its production, processing, characteristics, and cementitious properties. J Mater Civ Eng 16:230-236

Socrates G (1994) Infrared characteristic group frequencies. Tables and Charts. Wiley, Chichester

Soria J, Sanz J, Sobrados I, Coronado JM, Maira AJ, Hernández-Alonso MD, Fresno F (2007) FTIR and NMR study of the adsorbed water on nanocrystalline snatase. J Phys Chem C 111:10590-10596

Thommes M, Kaneko K, Neimark AV, Olivier JP, Rodriguez-Reinoso F, Rouquerol J, Sing KS (2015) Physisorption of gases, with special reference to the evaluation of surface area and pore size distribution (IUPAC Technical Report). Pure Appl Chem 87:1051-1069

Van Gerven T, Van Keer E, Arickx S, Jaspers M, Wauters G, Vandecasteele C (2005) Carbonation of MSWI-bottom ash to decrease heavy metal leaching, in view of recycling. Waste Manag 25:291-300

Wang T, Li H, Lu Q-L, Wu N, Jiang Y (2017) Preparation and characterization of Glauber's salt microcapsules for thermal energy storage. Tenside Surfactant Deterg 54:32-37

Xue Y, Hou H, Zhu S (2009) Adsorption removal of reactive dyes from aqueous solution by modified basic oxygen furnace slag: isotherm and kinetic study. Chem Eng J 147:272-279 
Yang L, Qian X, Wang Z, Li Y, Bai H, Li H (2018) Steel slag as low-cost adsorbent for the removal of phenanthrene and naphthalene. Adsorpt Sci Technol 36:1160-1177

Yi H, Xu G, Cheng H, Wang J, Wan Y, Chen H (2012) An overview of utilization of steel slag. Procedia Environ Sci 16:791-801

Yu J, Liang W, Wang L, Li F, Zou Y, Wang H (2015) Phosphate removal from domestic wastewater using thermally modified steel slag. J Environ Sci 31:81-88

Yuan H, Ma S, Wang X, Long H, Zhao X, Yang D, Lo WH, Tsang YH (2019) Ultra-high adsorption of cationic methylene blue on two dimensional titanate nanosheets. RSC Adv 9:5891-5894
Zhou Y-F, Haynes RJ (2011) A comparison of inorganic solid wastes as adsorbents of heavy metal cations in aqueous solution and their capacity for desorption and regeneration. Water Air Soil Pollut 218:457-470

Publisher's note Springer Nature remains neutral with regard to jurisdictional claims in published maps and institutional affiliations. 